\title{
Prognostic Factors for Node-Negative Advanced Gastric Cancer after Curative Gastrectomy
}

\author{
Eun Woo Lee, Woo Yong Lee ${ }^{1}$, and Ho-Seok Koo ${ }^{2}$ \\ Department of Surgery, Inje University Ilsan Paik Hospital, Inje University College of Medicine, Goyang, \\ Departments of ${ }^{1}$ Surgery and ${ }^{2}$ Internal Medicine, Inje University Seoul Paik Hospital, Inje University College of Medicine, Seoul, Korea
}

Purpose: Lymph node (LN) metastasis is the best prognostic indicator in non-distant metastatic advanced gastric cancer. This study aimed to assess the prognostic value of various clinicopathologic factors in node-negative advanced gastric cancer.

Materials and Methods: We retrospectively analyzed the clinical records of 254 patients with primary node-negative stage T2 4 gastric cancer. These patients were selected from a pool of 1,890 patients who underwent radical resection at Memorial Jin-Pok Kim Korea Gastric Cancer Center, Inje University Seoul Paik Hospital between 1998 and 2008.

Results: Of the 254 patients, 128 patients (50.4\%), 88 patients (34.6\%), 37 patients (14.6\%), and 1 patient (0.4\%) had T2, T3, $\mathrm{T} 4 \mathrm{a}$, and T4b tumors, respectively. In a univariate analysis, operation type, T-stage, venous invasion, tumor size, and less than 15 LNs significantly correlated with tumor recurrence and cumulative overall survival. In a multivariate logistic regression analysis, tumor size, venous invasion, and less than 15 LNs significantly and independently correlated with recurrence. In a multivariate Cox proportional hazards analysis, tumor size (hazard ratio [HR]: 2.926; 95\% confidence interval [Cl]: 1.173 7.300; P=0.021), venous invasion (HR: 3.985; 95\% Cl: 1.401 11.338; $\mathrm{P}=0.010$ ), and less than 15 LNs (HR: 0.092; 95\% Cl: 0.029 0.290; $\mathrm{P}<0.001$ ) significantly correlated with overall survival.

Conclusions: Node-negative gastric cancers recurred in $8.3 \%$ of the patients in our study. Tumor size, venous invasion, and less than $15 \mathrm{LNs}$ reliably predicted recurrence as well as survival. Aggressive postoperative treatments and timely follow-ups should be considered in cases with these characteristics.

Key Words: Lymph nodes; Prognosis; Stomach neoplasms

\section{Introduction}

Gastric cancer is the fourth most common cancer in the world. $^{1,2}$ A frequent cause of cancer-related death, it is largely responsible for the high mortality rates in East Asia. Despite decreases in its incidence and mortality rates, it remains the most

Correspondence to: Woo Yong Lee

Department of Surgery, Inje University Seoul Paik Hospital, Inje University College of Medicine, 9 Mareunnae-ro, Jung-gu, Seoul 04551, Korea

Tel: +82-2-2270-0247, Fax: +82-2-2270-0250

E-mail: yongaaa5972@naver.com

Received June 17, 2016

Revised August 15, 2016

Accepted August 29, 2016 common cancer in Korea. ${ }^{3}$

The standard surgical procedure for resectable advanced gastric cancer is D2 lymphadenectomy with radical gastrectomy. At least 15 dissected lymph nodes (LNs) are required for accurate histological classification of the postoperative LN metastatic stage according to the TNM staging system of the Union for International Cancer Control/American Joint Committee on Cancer (UICC/ AJCC). ${ }^{4-7}$ In the 7 th version of the TNM system, T-stages are subcategorized and $\mathrm{N}$-stages are more granular. ${ }^{7}$ The efficacies of $\mathrm{T}-$ and $\mathrm{N}$-staging are controversial, but $\mathrm{N}$-stage is generally considered a much stronger prognostic indicator than is $\mathrm{T}$-stage. There are only a few reports on node-negative advanced gastric cancer, and the most recent have focused on lymphatic invasion. 89 
Chemotherapy is currently not indicated for gastric cancers at a stage of less than T3 without LN metastasis. ${ }^{10}$ The aim of this study was to determine the clinicopathological characteristics of and prognostic factors for $\mathrm{LN}$-negative advanced gastric cancer (T2 4NOM0).

\section{Materials and Methods}

A total of 1,890 patients underwent curative gastrectomy for gastric adenocarcinoma at the Memorial Jin-Pok Kim Korea Gastric Cancer Center, Inje University Seoul Paik Hospital, between September 1998 and December 2008. Of these patients, our study retrospectively enrolled 254 patients who had primary node-negative gastric cancer, stage T2 4. The exclusion criteria included metachronous gastrointestinal cancer, a previous history of surgery for gastric cancer, and palliative surgery. The patients in our study did not receive systemic chemotherapy or radiotherapy before surgery.

All patients underwent radical gastrectomy with D2 LN dissection, as defined by the Japanese Gastric Cancer Association. ${ }^{6}$ They also received adjuvant immunochemotherapy for advanced and node-positive early gastric cancer. The regimen for adjuvant immunochemotherapy was as follows: OK-432 (Streptococcus pyogenes preparation) at 1.0 Klinische Einheit (day 5 after surgery, injected) and mitomycin $\mathrm{C}$ at $4 \mathrm{mg} / 50 \mathrm{~kg}$ and 5-fluorouracil (5-FU) at $800 \mathrm{mg} / 50 \mathrm{~kg}$ (twice per week for 2 consecutive weeks beginning day 8 after surgery and once per week after 6 weeks, injected). After completing this regimen, patients took oral $5-\mathrm{FU}$ (800 mg/50 kg per day) for 2 years.

Clinicopathological data were extracted from the computerized medical records of the patients. We analyzed the following information obtained from pathological examinations: clinical stage, $\mathrm{T}$-stage, tumor size, operation type, histologic type, venous invasion, lymphatic invasion, neural invasion, Lauren's classification, tumor location, and the number of dissected LN.

Follow-up assessments were performed every 3 months for the first 2 years after surgery and yearly thereafter. The followup procedures included medical history documentation, physical examination, routine blood testing including measurement of tumor marker (carcinoembryonic antigen and carbohydrate antigen 19-9) levels, upper endoscopy, chest radiography, abdominal ultrasonography, and computed tomography. Biopsy and radiologic imaging were used to confirm cancer recurrence. Recurrence was classified as locoregional, hematogenous, peritoneal dissemina- tion, or multiple metastases. Follow-ups were performed until December 2013 or the patient was lost to follow-up. The mean duration of the follow-up period was 67 months (range, 1 162 months).

The study was reviewed and approved by the Seoul Paik Hospital Institutional Review Board (IIT-2016-215).

For statistical analysis, receiver operating characteristic (ROC) analysis was used to determine the optimal cutoff values for continuous variables. Univariate associations were assessed by using logistic, Kaplan-Meier, and log-rank tests. Two multivariate analyses of the prognostic factors for recurrence were performed, one using logistic regression and the other using the Cox proportional hazards model.

The statistical analysis were performed using SPSS ver. 12.0 (SPSS Inc., Chicago, IL, USA).

\section{Results}

\section{Incidence and patterns of recurrence}

Our study included 254 patients who underwent curative surgery and whose pathologic diagnosis was node-negative advanced gastric cancer; 128 patients (50.4\%), 88 patients (34.6\%), 37 patients $(14.6 \%)$, and 1 patient $(0.4 \%)$ had T2, T3, T4a, and T4b tumors, respectively. Tumor recurrence occurred in 21 patients $(8.3 \%)$ and was locoregional in 6 patients $(28.6 \%)$, hematogenous in 6 patients $(28.6 \%)$, peritoneal dissemination in 4 patients (19.0\%), and multiple metastases in 5 patients (23.8\%) (Fig. 1).

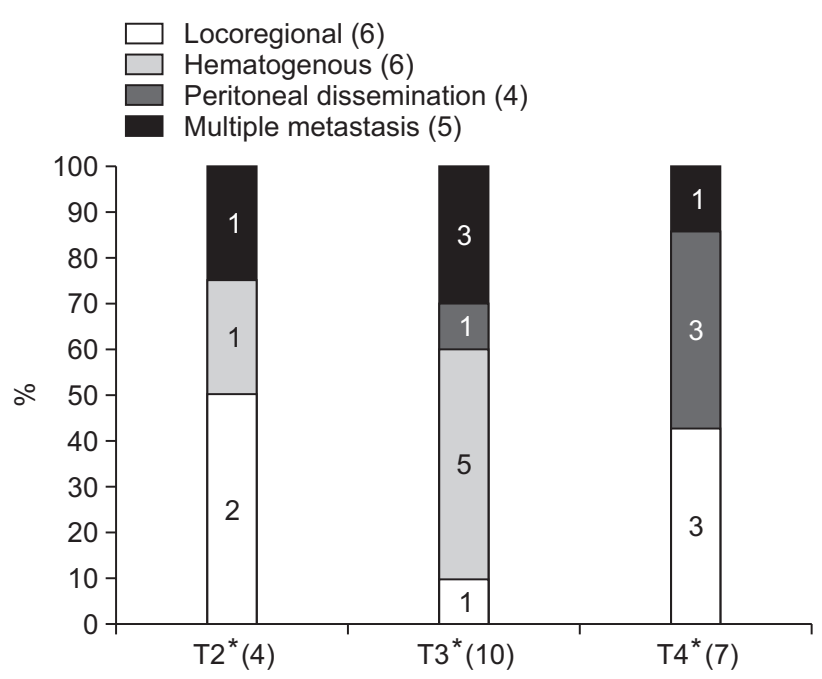

Fig. 1. Recurrence patterns according to T-stage. ${ }^{\star}$ Classification according to the TNM staging system of the Union for International Cancer Control/American Joint Committee on Cancer 7th edition. 


\begin{tabular}{cccccc}
\hline & & & & \multicolumn{2}{c}{$95 \%$ CI } \\
\cline { 5 - 6 } \cline { 4 - 5 } LN & AUC & P-value & Low & High \\
\hline 10 & 0.194 & 0.291 & & 0.145 & 0.242 \\
20 & 0.459 & 0.809 & & 0.113 & 0.806 \\
29 & 0.597 & 0.508 & & 0.445 & 0.748 \\
38 & 0.949 & 0.001 & 0.895 & 1.000 \\
47 & 0.623 & 0.269 & 0.480 & 0.765 \\
\hline
\end{tabular}

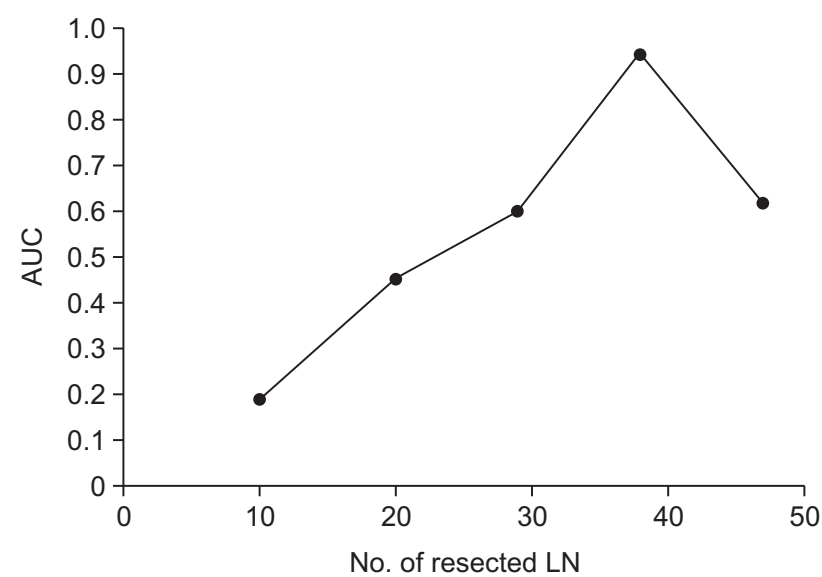

Fig. 2. The optimal cutoff value of LN was obtained by receiver operating characteristic analysis. $\mathrm{CI}=$ confidence interval; $\mathrm{LN}=$ lymph node; $\mathrm{AUC}$ $=$ area under curve.

Table 1. Patient demographics and clinicopathologic characteristics and correlation with recurrence

\begin{tabular}{|c|c|c|c|}
\hline Variable & $\begin{array}{c}\text { No. of } \\
\text { patients }\end{array}$ & $\begin{array}{l}\text { No. of } \\
\text { recurrences }\end{array}$ & P-value \\
\hline Sex & & & 0.895 \\
\hline Male & 152 & 14 & \\
\hline Female & 81 & 7 & \\
\hline Age (yr) & & & 0.538 \\
\hline$\leq 60$ & 105 & 8 & \\
\hline$>60$ & 128 & 13 & \\
\hline Operation type & & & 0.021 \\
\hline Partial gastrectomy & 158 & 9 & \\
\hline Total gastrectomy & 75 & 12 & \\
\hline T-stage* & & & 0.026 \\
\hline 2 & 123 & 5 & \\
\hline 3 & 79 & 9 & \\
\hline $4 \mathrm{a}$ & 30 & 7 & \\
\hline $4 \mathrm{~b}$ & 1 & 0 & \\
\hline Venous invasion & & & 0.025 \\
\hline Negative & 213 & 16 & \\
\hline Positive & 20 & 5 & \\
\hline Lymphatic invasion & & & 0.958 \\
\hline Negative & 79 & 7 & \\
\hline Positive & 154 & 14 & \\
\hline
\end{tabular}

The current TNM system requires that a minimum of 15 LNs (cutoff value $=15$ ) be collected via standard gastrectomy. In our study cohort, the total number of resected LNs nodes was 11,270, and the median number of resected LNs was 43. Less than 15 LNs were resected in only 11 patients (4.3\%; the $\mathrm{LN}<15$ group). Based on ROC analysis, the optimal cutoff value for dissected
Table 1. Continued

\begin{tabular}{|c|c|c|c|}
\hline Variable & $\begin{array}{c}\text { No. of } \\
\text { patients }\end{array}$ & $\begin{array}{c}\text { No. of } \\
\text { recurrences }\end{array}$ & P-value \\
\hline Neural invasion & & & 0.59 \\
\hline Negative & 86 & 9 & \\
\hline Positive & 147 & 12 & \\
\hline Histology & & & 0.136 \\
\hline Differentiated & 69 & 3 & \\
\hline Undifferentiated & 164 & 18 & \\
\hline Signet ring cell or mucinous component & & & 0.762 \\
\hline Negative & 141 & 12 & \\
\hline Positive & 92 & 9 & \\
\hline Lauren's classification & & & 0.944 \\
\hline Intestinal & 97 & 9 & \\
\hline Diffuse & 96 & 9 & \\
\hline Mixed & 40 & 3 & \\
\hline Tumor size $(\mathrm{cm})$ & & & 0.024 \\
\hline$\leq 4.7$ & 137 & 7 & \\
\hline$>4.7$ & 96 & 14 & \\
\hline Tumor location in the stomach & & & 0.979 \\
\hline Lower one-third & 79 & 7 & \\
\hline Mid & 108 & 10 & \\
\hline Upper & 44 & 4 & \\
\hline Entire & 2 & 0 & \\
\hline \multicolumn{4}{|l|}{ Resected lymph nodes } \\
\hline$<15$ & 7 & 4 & 0.001 \\
\hline$\geq 15$ & 226 & 17 & \\
\hline$<38$ & 76 & 8 & 0.609 \\
\hline$\geq 38$ & 157 & 13 & \\
\hline
\end{tabular}

${ }^{\star}$ Classification according to the TNM staging system of the Union for International Cancer Control/American Joint Committee on Cancer 7 th edition. 

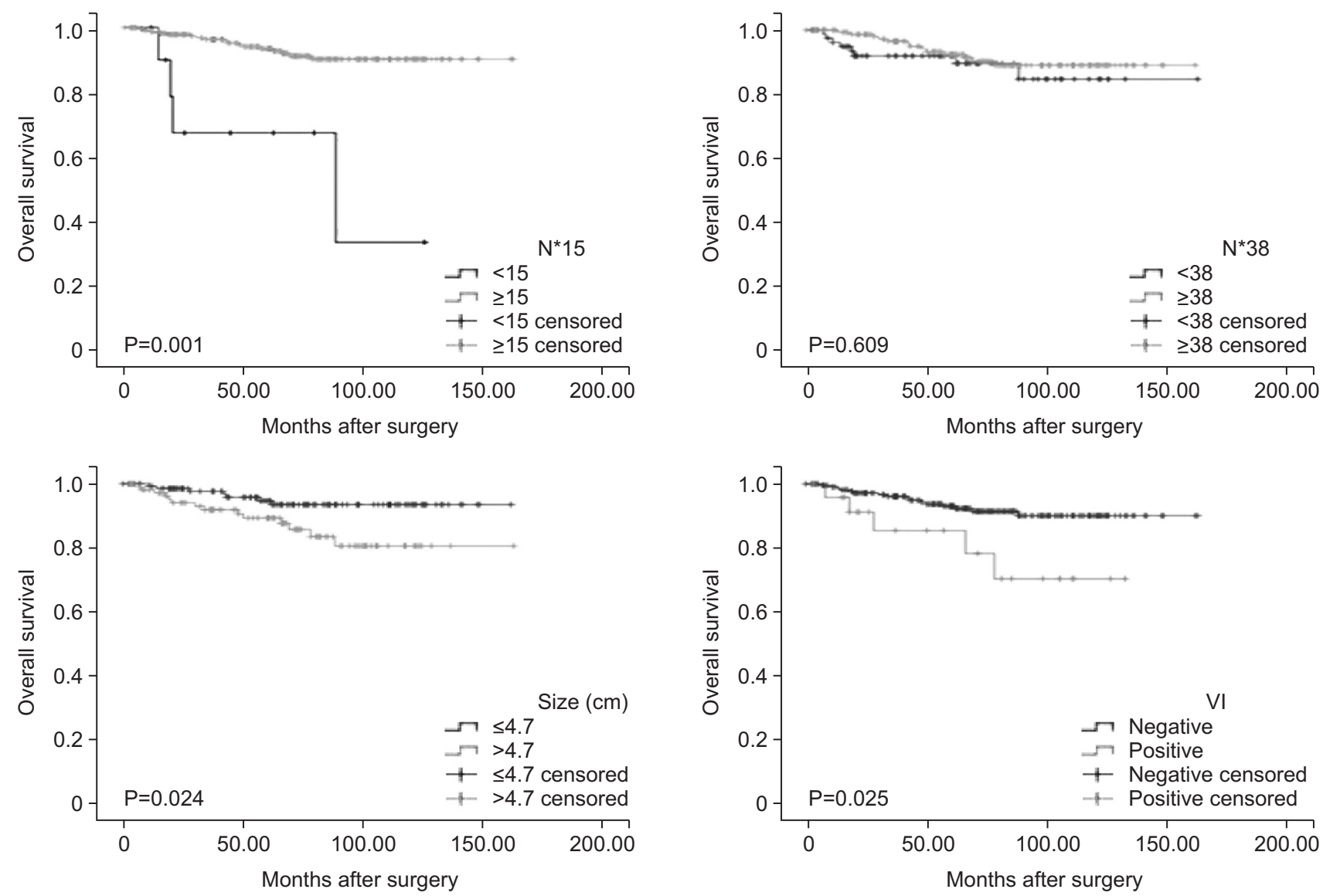

Fig. 3. Kaplan-Meier analysis of overall survival according to significant clinicopathologic factors with node-negative advanced gastric cancer. VI = venous invasion. ${ }^{\star}$ Resected lymph nodes.

LNs was 38 (Fig. 2). In our study cohort, 84 patients (33.1\%) had less than 38 resected LNs (the $\mathrm{LN}<38$ group) and 170 patients (66.9\%) had more than 38 resected LNs (the $\mathrm{LN} \geq 38$ group). Tumors recurred in 4 patients $(57.1 \%)$ in the $\mathrm{LN}<15$ group, 17 patients $(7.52 \%)$ in the $\mathrm{LN} \geq 15$ group, 8 patients $(10.5 \%)$ in the $\mathrm{LN}<38$ group, and 13 patients (8.2\%) in the $\mathrm{LN} \geq 38$ group (Table 1).

\section{Analysis of clinicopathologic factors and recurrence}

Table 1 lists the clinicopathologic factors of the patients with node-negative advanced gastric cancer, as well as the relationships between these factors and recurrence. Recurrence correlated significantly with operation type $(\mathrm{P}=0.021)$, $\mathrm{T}$-stage $(\mathrm{P}=0.026)$, venous invasion $(\mathrm{P}=0.025)$, tumor size $(\mathrm{P}=0.024)$, and $\mathrm{LN}$ number $<15(\mathrm{P}=0.001)$. A multivariate logistic regression analysis showed that tumor size $(\mathrm{P}=0.021)$, venous invasion $(\mathrm{P}=0.019)$, and $\mathrm{LN}$ number $<15(\mathrm{P}=0.001)$ were independent predictors of recurrence.
Table 2. Multivariate Cox regression analysis for overall survival

\begin{tabular}{lccr}
\hline & $\begin{array}{c}\text { Hazard } \\
\text { ratio }\end{array}$ & $\begin{array}{c}95 \% \text { confidence } \\
\text { interval }\end{array}$ & P-value \\
\hline Tumor size $(\mathrm{cm})$ & 2.926 & $1.173 \sim 7.300$ & 0.021 \\
Venous invasion & 3.985 & $1.401 \sim 11.338$ & 0.010 \\
$<15$ resected lymph nodes & 0.092 & $0.029 \sim 0.290$ & $<0.001$ \\
\hline
\end{tabular}

\section{Overall survival of patients with node-negative advanced gastric cancer}

In a multivariate analysis using logistic regression, cumulative overall survival (OS) was significantly associated with operation type $(\mathrm{P}=0.043)$, $\mathrm{T}$-stage $(\mathrm{P}=0.026)$, venous invasion $(\mathrm{P}=0.016)$, tumor size $(\mathrm{P}=0.024)$, and $\mathrm{LN}$ number $<15(\mathrm{P}<0.001)$, but not $\mathrm{LN}$ number<38 (Fig. 3). In a multivariate analysis using the Cox proportional hazards model, cumulative OS was significantly associated with tumor size $(\mathrm{P}=0.021)$, venous invasion $(\mathrm{P}=0.010)$, and LN number $<15(\mathrm{P}<0.001)$ (Table 2). 


\section{Discussion}

Despite improvements in survival rates attributable to early detection and radical lymphadenectomy, gastric cancer remains one of the most common causes of death from cancer worldwide, as well as the fourthmost common cancer worldwide. ${ }^{1,2}$ Because concrete evidence supports its use in stage II and III gastric cancer, adjuvant chemotherapy is widely accepted as a standard treatment for gastric cancer patients with a high risk of recurrence. Hence, $\mathrm{N}$-stage is the most significant prognostic indicator in gastric cancer. However, adjuvant chemotherapy is not recommended for pT3N0 gastric cancers despite prognostic similarities between the stage IIA gastric cancer subgroups. ${ }^{10}$ The decision to administer adjuvant chemotherapy to patients withT3N0 gastric cancer is currently left to the clinicians' discretion. This study, which examined T2 4N0 gastric cancers, found that T-stage was a significant prognostic factor for recurrence and OS in a univariate analysis, but not a multivariate analysis using the Cox proportional hazards model.

Among the various prognostic factors previously reported, tumor size is especially important in node-negative advanced gastric cancer. Adachi et al. ${ }^{11}$ identified gastric tumor size as a simple prognostic indicator. Kim et al. ${ }^{12}$ found that patients with nodenegative gastric cancers had favorable outcomes, whereas those with relatively large tumors and serosal invasion had unfavorable outcomes. Yokota et al. ${ }^{13}$ showed that tumor size predicted survival rates in patients with gastric cancer. Our study shows that gastric tumor size and prognosis are closely associated.

In the study by Zhang et al, ${ }^{14}$ the number of retrieved LNs was an independent prognostic factor in node-negative gastric cancer, and retrieval of more than 15 LNs correlated with improved survival rates. In that study, less than 15 LNs were retrieved from most patients (74 of 106 patients, 69.8\%). In our study, the average number of retrieved LNs was 44.3, and in almost all patients (243 of 254 patients, $95.7 \%$ ), at least 15 were retrieved. The prognosis of patients with at least 15 retrieved LNs was significantly better than that of patients with less than 15 retrieved LNs. In the study by $\mathrm{He}$ et al. ${ }^{15}$ of patients with advanced node-negative cancer, survival rates improved as the number of retrieved LNs following radical gastrectomy increased. In that study, the cutoff value for retrieved LNs was 18 as determined via ROC analysis, and the prognosis of patients with more than 18 retrieved LNs was significantly better than that of patients with 18 or fewer retrieved LNs. We also used ROC analysis to determine the optimal cutoff value for LNs in node-negative gastric cancer. We calculated the area under ROC curves at different cutoff values corresponding to different OS times and obtained a substantially greater cutoff value (38) than did He et al. ${ }^{15}$ However, there was no significant difference between the $\geq 38$ and $<38$ groups in terms of recurrence. Therefore, at least 15 LNs should be collected, as recommended by the UICC/AJCC cancer staging manual.

Lymphovascular invasion (LVI) is recognized as a negative prognostic factor in several malignancies, including gastric cancer. $^{3,5-7,16}$ Previous studies showing that LVI is an independent predictor of worse survival in gastric cancer include the gene expression analysis by Dicken et al. ${ }^{17}$ and the comparative analysis by Lee et al. ${ }^{18}$ of patients with N0 versus N1 gastric cancer. In our study, however, there was no significant relationship between venous invasion and lymphatic invasion. Furthermore, venous invasion correlated significantly with OS and recurrence, whereas lymphatic invasion did not. These findings may reflect our study's focus on node-negative patients only.

In conclusion, we recommend the development of comprehensive, individualized treatment plans for patients with nodenegative gastric cancer. Our analysis of these cancers showed that tumor size, venous invasion, and at least 15 retrieved LNs were independent prognostic indicators of survival. Further evaluation of prognostic factors is needed to determine whether treatments such as adjuvant therapy benefit patients with node-negative advanced gastric cancer.

\section{Conflicts of Interest}

No potential conflict of interest relevant to this article was reported.

\section{References}

1. Siegel R, Ma J, Zou Z, Jemal A. Cancer statistics, 2014. CA Cancer J Clin 2014;64:9-29.

2. DeSantis CE, Lin CC, Mariotto AB, Siegel RL, Stein KD, Kramer JL, et al. Cancer treatment and survivorship statistics, 2014. CA Cancer J Clin 2014;64:252-271.

3. Jung KW, Won YJ, Kong HJ, Oh CM, Cho H, Lee DH, et al. Cancer statistics in Korea: incidence, mortality, survival, and prevalence in 2012. Cancer Res Treat 2015;47:127-141.

4. Cuschieri SA, Hanna GB. Meta-analysis of D1 versus D2 gastrectomy for gastric adenocarcinoma: let us move on to an- 
other era. Ann Surg 2014;259:e90.

5. Memon MA, Subramanya MS, Khan S, Hossain MB, Osland E, Memon B. Meta-analysis of D1 versus D2 gastrectomy for gastric adenocarcinoma. Ann Surg 2011;253:900-911.

6. Japanese Gastric Cancer Association. Japanese classification of gastric carcinoma: 2nd English edition. Gastric Cancer 1998;1:10-24.

7. Washington K. 7th edition of the AJCC cancer staging manual: stomach. Ann Surg Oncol 2010;17:3077-3079.

8. Kim SS, Choi BY, Seo SI, Jung MY, Choi HS, Ahn SM, et al. The comparison between 6th and 7th International Union against Cancer/American Joint Committee on Cancer classification for survival prognosis of gastric cancer. Korean J Gastroenterol 2011;58:258-263.

9. Kim JH, Kim CW, Choi NK, Kwak JH, Choi KM, Jang HJ, et al. The comparison between 6th and 7th UICC/AJCC N Stage for prognostic significance in gastric cancer. J Korean Surg Soc 2010;79:202-206.

10. Imamura T, Komatsu S, Ichikawa D, Kubota T, Okamoto K, Konishi H, et al. Poor prognostic subgroup in T3N0 stage IIA gastric cancer, suggesting an indication for adjuvant chemotherapy. J Surg Oncol 2015;111:221-225.

11. Adachi Y, Oshiro T, Mori M, Maehara Y, Sugimachi K. Tumor size as a simple prognostic indicator for gastric carcinoma. Ann Surg Oncol 1997;4:137-140.
12. Kim DY, Seo KW, Joo JK, Park YK, Ryu SY, Kim HR, et al. Prognostic factors in patients with node-negative gastric carcinoma: a comparison with node-positive gastric carcinoma. World J Gastroenterol 2006;12:1182-1186.

13. Yokota T, Ishiyama S, Saito T, Teshima S, Yamada Y, Iwamoto $\mathrm{K}$, et al. Is tumor size a prognostic indicator for gastric carcinoma? Anticancer Res 2002;22:3673-3677.

14. Zhang BY, Yuan J, Cui ZS, Li ZW, Li XH, Lu YY. Evaluation of the prognostic value of the metastatic lymph node ratio for gastric cancer. Am J Surg 2014;207:555-565.

15. He H, Shen Z, Wang X, Qin J, Sun Y, Qin X. Survival benefit of greater number of lymph nodes dissection for advanced nodenegative gastric cancer patients following radical gastrectomy. Jpn J Clin Oncol 2016;46:63-70.

16. Rausei S, Dionigi G, Ruspi L, Proserpio I, Galli F, Tirotta F, et al. Lymph node staging in gastric cancer: new criteria, old problems. Int J Surg 2013;11 Suppl 1:S90-S94.

17. Dicken BJ, Graham K, Hamilton SM, Andrews S, Lai R, Listgarten J, et al. Lymphovascular invasion is associated with poor survival in gastric cancer: an application of gene-expression and tissue array techniques. Ann Surg 2006;243:64-73.

18. Lee JH, Kim MG, Jung MS, Kwon SJ. Prognostic significance of lymphovascular invasion in node-negative gastric cancer. World J Surg 2015;39:732-739. 